\title{
Diagnostic Errors
}

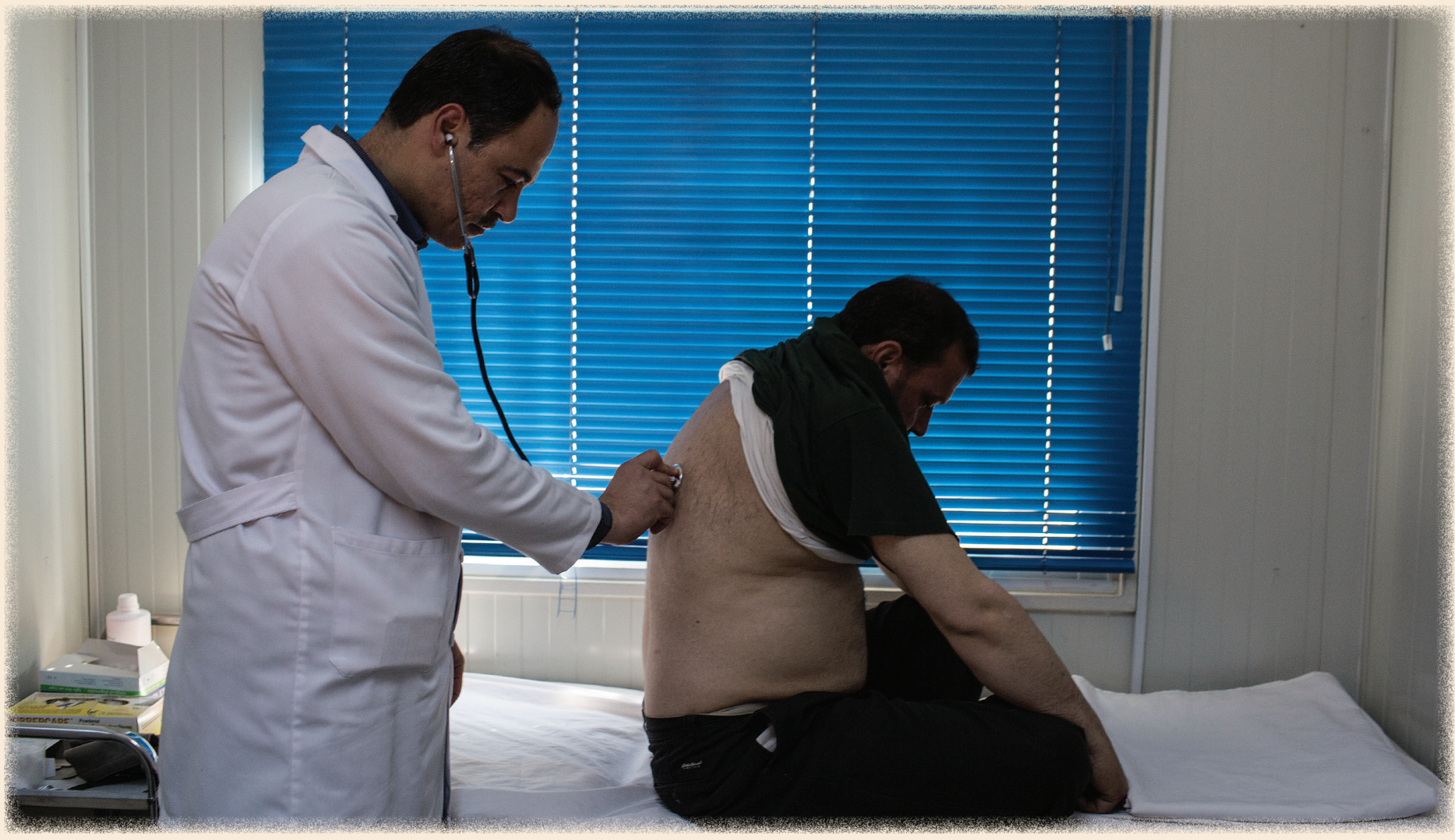

Technical Series on Safer Primary Care 
Diagnostic Errors: Technical Series on Safer Primary Care

ISBN 978-92-4-151163-6

(c) World Health Organization 2016

Some rights reserved. This work is available under the Creative Commons Attribution-NonCommercialShareAlike 3.0 IGO licence (CC BY-NC-SA 3.0 IGO; https://creativecommons.org/licenses/by-nc-sa/3.0/igo).

Under the terms of this licence, you may copy, redistribute and adapt the work for non-commercial purposes, provided the work is appropriately cited, as indicated below. In any use of this work, there should be no suggestion that WHO endorses any specific organization, products or services. The use of the WHO logo is not permitted. If you adapt the work, then you must license your work under the same or equivalent Creative Commons licence. If you create a translation of this work, you should add the following disclaimer along with the suggested citation: "This translation was not created by the World Health Organization (WHO). WHO is not responsible for the content or accuracy of this translation. The original English edition shall be the binding and authentic edition".

Any mediation relating to disputes arising under the licence shall be conducted in accordance with the mediation rules of the World Intellectual Property Organization (http://www.wipo.int/amc/en/mediation/ rules).

Suggested citation. Diagnostic Errors: Technical Series on Safer Primary Care. Geneva: World Health Organization; 2016. Licence: CC BY-NC-SA 3.0 IGO.

Cataloguing-in-Publication (CIP) data. CIP data are available at http://apps.who.int/iris.

Sales, rights and licensing. To purchase WHO publications, see http://apps.who.int/bookorders. To submit requests for commercial use and queries on rights and licensing, see http://www.who.int/about/licensing.

Third-party materials. If you wish to reuse material from this work that is attributed to a third party, such as tables, figures or images, it is your responsibility to determine whether permission is needed for that reuse and to obtain permission from the copyright holder. The risk of claims resulting from infringement of any third-party-owned component in the work rests solely with the user.

General disclaimers. The designations employed and the presentation of the material in this publication do not imply the expression of any opinion whatsoever on the part of WHO concerning the legal status of any country, territory, city or area or of its authorities, or concerning the delimitation of its frontiers or boundaries. Dotted and dashed lines on maps represent approximate border lines for which there may not yet be full agreement.

The mention of specific companies or of certain manufacturers' products does not imply that they are endorsed or recommended by WHO in preference to others of a similar nature that are not mentioned. Errors and omissions excepted, the names of proprietary products are distinguished by initial capital letters.

All reasonable precautions have been taken by WHO to verify the information contained in this publication. However, the published material is being distributed without warranty of any kind, either expressed or implied. The responsibility for the interpretation and use of the material lies with the reader. In no event shall WHO be liable for damages arising from its use. 


\section{Contents}

$\begin{array}{ll}\text { Preface } & 1\end{array}$

1 Introduction 3

1.1 Scope 3

1.2 Approach 3

1.3 Defining diagnostic errors 3

2 Burden of diagnostic errors $\quad 5$

3 Causes of diagnostic errors 6

$\begin{array}{ll}3.1 \text { Key causes } & 6\end{array}$

$\begin{array}{ll}3.2 \text { Conditions involved } & 7\end{array}$

4 Potential solutions $\quad 9$

4.1 Improving education and skills 9

4.2 Empowering patients 9

$\begin{array}{ll}4.3 \text { Improving health systems } & 10\end{array}$

$\begin{array}{ll}4.4 \text { Health information technology } & 10\end{array}$

4.5 Improving access to testing $\quad 12$

$\begin{array}{ll}4.6 \text { Learning from errors } & 12\end{array}$

$\begin{array}{ll}4.7 \text { Further research } & 13\end{array}$

5 Practical next steps $\quad 14$

6 Concluding remarks 16

$\begin{array}{ll}\text { Contributors } & 22\end{array}$

$\begin{array}{ll}\text { References } & 24\end{array}$ 


\section{Preface}

\section{Safer Primary Care}

Health services throughout the world strive to provide care to people when they are unwell and assist them to stay well. Primary care services are increasingly at the heart of integrated people-centred health care in many countries. They provide an entry point into the health system, ongoing care coordination and a personfocused approach for people and their families. Accessible and safe primary care is essential to achieving universal health coverage and to supporting the United Nations Sustainable Development Goals, which prioritize healthy lives and promote well-being for all.

Health services work hard to provide safe and high quality care, but sometimes people are inadvertently harmed. Unsafe health care has been recognized as a global challenge and much has been done to understand the causes, consequences and potential solutions to this problem. However, the majority of this work up to now has focused on hospital care and there is, as a result, far less understanding about what can be done to improve safety in primary care.

Provision of safe primary care is a priority. Understanding the magnitude and nature of harm in primary care is important because most health care is now offered in this setting. Every day, millions of people across the world use primary care services. Therefore, the potential and necessity to reduce harm is very considerable. Good primary care may lead to fewer avoidable hospitalizations, but unsafe primary care can cause avoidable illness and injury, leading to unnecessary hospitalizations, and in some cases, disability and even death.

Implementing system changes and practices are crucial to improve safety at all levels of health care. Recognizing the paucity of accessible information on primary care, World Health Organization (WHO) set up a Safer Primary Care Expert Working Group. The Working Group reviewed the literature, prioritized areas in need of further research and compiled a set of nine monographs which cover selected priority technical topics. WHO is publishing this technical series to make the work of these distinguished experts available to everyone with an interest in Safer Primary Care.

The aim of this technical series is to provide a compendium of information on key issues that can impact safety in the provision of primary health care. It does not propose a "one-size-fits-all" approach, as primary care is organized in different ways across countries and also often in different ways within a given country. There can be a mix of larger primary care or group services with shared resources and small services with few staff and resources. Some countries have primary care services operating within strong national support systems, while in other 
countries it consists mainly of independent private practices that are not linked or well-coordinated. The approach to improving safety in primary care, therefore, needs to consider applicability in each country and care setting.

This technical series covers the following topics:

\section{Patients}

- Patient engagement

\section{Health workforce}

- Education and training

- Human factors

\section{Care processes}

- Administrative errors

- Diagnostic errors

- Medication errors

- Multimorbidity

- Transitions of care

Tools and technology

- Electronic tools

WHO is committed to tackling the challenges of patient safety in primary care, and is looking at practical ways to address them. It is our hope that this technical series of monographs will make a valuable and timely contribution to the planning and delivery of safer primary care services in all WHO Member States. 


\section{Introduction}

\subsection{Scope}

Diagnosis is one of the most important tasks performed by primary care providers. Diagnostic errors can lead to patient harm from wrong or delayed testing or treatment. They have emerged as a global priority in patient safety.

This monograph raises awareness among the World Health Organization (WHO) Member States about strategies that could be implemented to reduce diagnostic errors in primary care. After outlining the approach taken to compile information, the monograph describes the importance of examining diagnostic errors, the most common types of diagnostic errors in primary care, and potential solutions.

\subsection{Approach}

To compile information for this monograph, WHO sought the advice of experts in the field recommended by the Safer Primary Care Expert Working Group and reviewed relevant research and published literature.

International experts in delivering safe primary care provided feedback, examples of strategies that have demonstrated success around the world and practical suggestions about potential priorities for countries to improve the safety of primary care services.

\subsection{Defining diagnostic errors}

Correct and timely diagnosis relies on many factors, including the knowledge, experience and skill of primary care providers and the resources available to them. Diagnosis is a high-risk area for errors in primary care. Primary care providers typically see high numbers of people and their conditions are often difficult to diagnose due to potentially difficult clinical presentations (1). Primary care providers may have limited experience with uncommon diseases and varying access to diagnostic tests. The term "provider" is used throughout this monograph to refer to the primary care workforce.

A diagnostic error emerges when a diagnosis is missed, inappropriately delayed or is wrong (2). Diagnoses can be completely missed (cancer missed despite symptoms), wrong (patients told they have one diagnosis when there is evidence of another) or delayed (abnormal test result suggestive of cancer, but no one has told the patient). There may be overlaps in these classifications.

Diagnoses often occur over time, rather than at one point in time, including initial assessment, performing and interpreting diagnostic tests, follow-up and tracking 
of diagnostic information, referral-related communication and coordination, and patient behaviour, adherence and engagement. Diagnostic errors can occur at each of these points (3).

Diagnostic errors are a failure to provide an accurate and timely explanation of the patient's health problems or communicate that explanation to the patient (4). They are considered as missed opportunities to make a correct or timely diagnosis based on available evidence. The missed opportunity may result from cognitive or system factors or both. To reduce hindsight bias, there should be evidence of omission (failure to do the right thing) or commission (doing something wrong) at the point in time at which the error occurred $(5,6)$. Figure 1 depicts the relationship between diagnostic errors, missed opportunities and patient harm. Opportunities could be missed by providers, care teams, systems or the patient. A preventable error or delay in diagnosis may occur due to factors outside a provider's immediate control and have little to do with the provider's actions (7).

Figure 1. Conceptual model of missed opportunities in diagnosis $(5,6)$

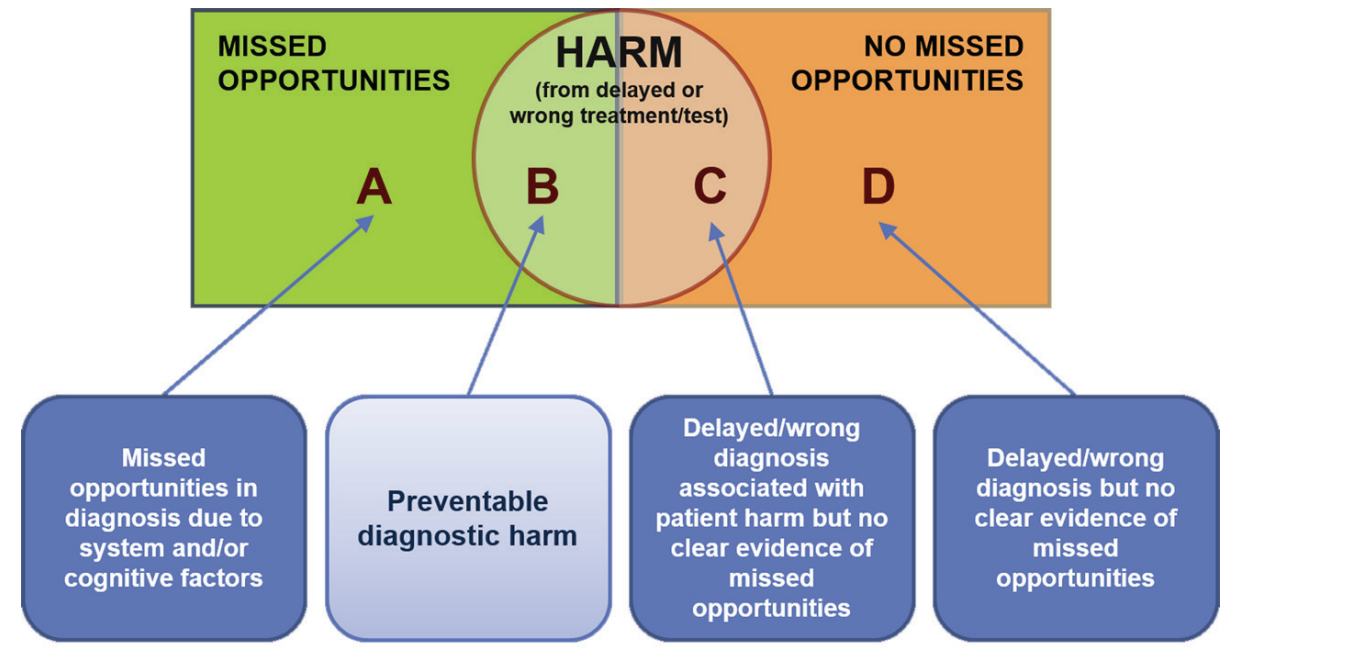

Rather than target all delays in diagnosis, health care organizations could hone their detection strategies by focusing on clear areas of needed improvement (for example, Area B) and choose at least one diagnostic error detection strategy.

Source: reproduced with permission from the publishers (reference numbers 5 and 6). 


\section{Burden of diagnostic errors}

Errors in hospitals have been found to be significant, but this monograph suggests that it is also important to be aware of diagnostic errors in primary care. Diagnostic errors are relatively common in primary care (8) and most people will likely experience a diagnostic error in their lifetime (4).

A study conducted in a high-income country found that approximately $5 \%$ of adults experienced diagnostic errors in outpatient settings each year. Over half of these errors had the potential for severe harm. The researchers suggested that this was likely to be an underestimate (4) and the rate of diagnostic errors in low-income countries may be much higher.

The extent of diagnostic errors related to children is unknown. However, a survey of children's doctors in a high-income country found that more than one-half reported making a diagnostic error at least once or twice per month and recognized that they made harmful errors at least once or twice a year (7).

In low- and middle-income countries, there may be even greater challenges due to limited access to diagnostic testing resources, a paucity of qualified primary care professionals or specialists and limited record-keeping systems. These factors may contribute to a higher rate of diagnostic errors in primary care (6).

Delays in diagnosing cancer are common. About $7 \%$ of abnormal test results are not communicated to patients, which can lead to a delay in diagnosis (8). Breakdowns in the referral process can also lead to diagnostic errors and delays (9). 


\section{Causes of diagnostic errors}

\subsection{Key causes}

All aspects of the diagnostic process are vulnerable to error. Studies of diagnostic error often reveal a number of root causes in each case. Causes may include cognitive errors, such as failure to synthesize the available evidence correctly or failure to use physical examination or test data appropriately. In fact, there is evidence that cognitive errors can be identified in over half of the cases of diagnostic error. System flaws may also contribute to diagnostic errors as a result of problems with communication or coordination of care, problems with the availability of medical record data and insufficient access to specialists (10).

A study in one developed country found that process breakdowns most frequently involved the patient-practitioner clinical encounter (79\%), followed by referral problems $(20 \%)$, patient-related factors $(16 \%)$, follow-up and tracking of diagnostic information (15\%) and performance and interpretation of diagnostic tests (14\%). Almost half of all diagnostic errors involved more than one of these processes. Patient-practitioner encounter breakdowns were primarily related to problems with history-taking $(56 \%)$, examination $(47 \%)$ or ordering diagnostic tests for further workup (57\%) (3).

A wide range of factors may contribute to diagnostic errors (Table 1).

Table 1. Factors that may contribute to diagnostic errors in primary care

\begin{tabular}{|l|l|}
\hline Factors & Possible issues contributing to error \\
\hline $\begin{array}{l}\text { Access to high quality } \\
\text { primary care }\end{array}$ & $\begin{array}{l}\text { Limited access due to lack of money, remoteness, } \\
\text { illiteracy, travel constraints or a limited number of } \\
\text { health care facilities. }\end{array}$ \\
\hline $\begin{array}{l}\text { Availability of health } \\
\text { care professionals and } \\
\text { specialists }\end{array}$ & $\begin{array}{l}\text { Lack of sufficient, competent health care } \\
\text { professionals, for example, due to lack of training, } \\
\text { outward migration or a poor employment situation. } \\
\text { Specialty expertise may not exist or may be limited } \\
\text { in number or quality. }\end{array}$ \\
\hline Teamwork & $\begin{array}{l}\text { Poor teamwork, lack of learning and feedback when } \\
\text { errors occur. }\end{array}$ \\
\hline $\begin{array}{l}\text { Availability of } \\
\text { diagnostic tests }\end{array}$ & $\begin{array}{l}\text { Diagnostic tests limited in scope, availability or } \\
\text { quality. }\end{array}$ \\
\hline Communication & Little or no sharing of medical information. \\
\hline
\end{tabular}




\begin{tabular}{|l|l|}
\hline Factors & Possible issues contributing to error \\
\hline Care coordination & $\begin{array}{l}\text { Consultations delayed or test results lost or a lack of } \\
\text { health records documenting care. }\end{array}$ \\
\hline Follow-up & $\begin{array}{l}\text { Limited follow-up reduces the ability for diagnostic } \\
\text { impressions to evolve. }\end{array}$ \\
\hline Affordability of care & $\begin{array}{l}\text { Care unaffordable or compromises other basic } \\
\text { needs such as food or housing. }\end{array}$ \\
\hline Training of health care & $\begin{array}{l}\text { Training is suboptimal, in particular lack of training } \\
\text { for clinical reasoning; certification and licensure } \\
\text { requirements are deficient. }\end{array}$ \\
\hline $\begin{array}{l}\text { Availability of health } \\
\text { informatics resources }\end{array}$ & $\begin{array}{l}\text { Health informatics resources, including internet } \\
\text { access, may not be available, especially in remote } \\
\text { areas; unaffordable subscription or download fees } \\
\text { for medical information. }\end{array}$ \\
\hline Culture & $\begin{array}{l}\text { Some cultures may be punitive, which discourage } \\
\text { sharing and inhibit learning; physician-centric } \\
\text { systems limit the value of the team. Patients may } \\
\text { feel it is more appropriate to be passive care } \\
\text { recipients. }\end{array}$ \\
\hline $\begin{array}{l}\text { Human factors and } \\
\text { cognitive issues }\end{array}$ & $\begin{array}{l}\text { The work environment and systems may be } \\
\text { subject to distractions, interruptions and a lack of } \\
\text { organization of information. }\end{array}$ \\
\hline
\end{tabular}

\subsection{Conditions involved}

Data about the most common conditions involved in diagnostic errors are mainly from high-income countries. A systematic review identified diagnostic difficulties and errors in primary care among people with cancer, heart attack, meningitis, dementia, iron deficiency anaemia, asthma, tremor in the elderly and human immunodeficiency virus (HIV) (1). A study of 190 cases of diagnostic errors found that errors were common in patients with pneumonia (7\%), decompensated congestive heart failure $(7 \%)$, acute renal failure $(5 \%)$, cancer $(5 \%)$ and urinary tract infection (5\%) (3). Another study identified errors most commonly involving infections, trauma and malignant neoplasms (11).

Overall, it appears that missed cancer, infections and cardiovascular disease comprise the leading categories of harmful diagnostic errors in primary care. Each of these is explored briefly in turn. 


\section{Cancer}

The burden of cancer is significant in countries across the world. Delayed cancer diagnosis is both harmful and costly. Cancer diagnosis is challenging especially because many cancers can present as nonspecific symptoms to primary care providers. However, efforts to increase diagnosis through screening may inadvertently lead to identifying benign or non-harmful cancers that do not require aggressive treatment.

\section{Infections}

Diagnostic errors are common in self-limiting infections, as well as in more serious infections. Viral infections are often misdiagnosed as bacterial infections, resulting in unnecessary use of antibiotics. The diagnosis of malaria can be particularly troublesome because key features, such as fever, are not specific (12). Almost 10\% of cases of tuberculosis may be misdiagnosed due to misinterpretation of test results and failure to use basic diagnostic tools, such as microbiology or imaging (13). Globally, diagnoses of children with pneumonia, dehydration from diarrhoea and malaria are often suboptimal (14).

\section{Cardiovascular disease}

In both children and adults, a delayed diagnosis of cardiovascular conditions can occur and may worsen clinical outcomes. Errors may occur when subtle premonitory symptoms are missed or disregarded in primary care. Identifying people for whom primary or secondary prevention is needed requires appropriate diagnosis and management of risk factors or predisposing conditions, such as diabetes, hypertension and high cholesterol levels.

\section{Paediatrics}

Globally, misdiagnoses may contribute to the nearly 7 million children who die each year, mainly from preventable causes (15). However, information about misdiagnosis in children is limited. A systematic review of malpractice claims in primary care identified 34 studies (all from high-income countries), of which only two provided data about paediatrics claims. Common conditions resulting in claims in children were meningitis, gastroenteritis, pneumonia, appendicitis, sepsis and malignancy (16). 


\section{Potential solutions}

Interventions to reduce diagnostic errors have focused on improving the knowledge and skills of providers as well as addressing systems issues, such as communication, record keeping and test ordering processes (17). However, evidence about the effectiveness of approaches to reduce diagnostic errors is limited (18). It is likely that a combination of interventions would be most effective.

\subsection{Improving education and skills}

Research suggests that providers may not always think through their decisions or interpret information well. Certain aspects of diagnostic reasoning might be more important, more common or more amenable to interventions. Interventions that could potentially improve clinical reasoning include training in how to practice reflectively and tools, such as mnemonics, checklists or online decision support tools that assist with differential diagnosis $(19,20)$. Embedding decision support tools in electronic health records provides point of care support for diagnosis and treatment. Having more robust evidence about which clinical features provide greatest diagnostic value in primary care settings is essential.

Improving the reliability of diagnosis requires better education of primary care providers. Trainees would benefit from explicit training in clinical reasoning, patient safety, human factors, critical thinking, managing uncertainty, cognitive heuristics and biases, test limitations, probability concepts, reliability science and systems thinking. Training focused on the causes and impact of diagnostic error might help providers become more competent in error prevention. Simulations and feedback can be a helpful way to learn.

\subsection{Empowering patients}

Engaging and empowering patients is a low-cost investment with a large potential benefit. Patients can act as a safety net by being empowered to continue to watch for new symptoms emerging over time. This involves educating patients to know what symptoms to look for, what the expected time course of their illness is and how to access care again if their condition does not improve. In addition, patients can be proactive in ensuring diagnostic test results are reviewed. They can prompt providers to think comprehensively about a differential diagnosis by asking about alternative diagnoses and accessing medical information on their own. They can also help to prevent diagnostic errors by participating in follow-up and feedback (21). 
Patient empowerment includes dispelling misconceptions, such as "no news is good news" from the doctor (which could contribute to failures in the follow-up of abnormal test results), and encouraging people to raise any concerns or fears without feeling intimidated. However, this can be challenging in areas where a more passive approach or hierarchical culture prevails.

Another monograph in this technical series explores ways to engage and empower patients to improve safety in more depth.

\subsection{Improving health systems}

Systems that work in urban environments with easy access to technical support might face different challenges from those that function in dispersed rural areas. The stage of economic development of the country or community also affects the options in health system design. However, in all health systems it is likely that diagnosis could be improved by enhancing access to care and appropriate expertise, ensuring the competency of providers and primary care teams, making available high-quality diagnostic testing services (e.g. radiology/laboratory) and providing a suitable work environment with safe and effective health information technology (IT) to help optimize care (22).

Relatively little is known about how best to measure the quality of primary care, particularly in lower resource settings. However, countries with stronger primary care systems have healthier people (23). There are large discrepancies globally in the number, type and dispersion of primary care providers. Government policies that build primary care as part of the overall healthcare system are essential. In areas where access to primary care is limited, health care providers other than doctors can deliver primary care, but it is important that these providers have appropriate training and support.

Low-income countries may wish to prioritize reducing diagnostic errors in conditions that can be improved with a relatively minor investment. For example, these could include cancer or infection diagnoses or improved follow-up of patients seen for emergency care. Health IT could be leveraged to improve diagnosis at multiple levels and could facilitate both the measurement and the reduction of errors (24).

\subsection{Health information technology}

Many forms of health IT could help to reduce diagnostic errors in countries across the world. If internet access is available, remote consultation and diagnosis can be useful. Remote readings of radiology imaging, cardiology, ophthalmology, pathology and dermatology have been used successfully (25). This increases access to subspecialty expertise, often in real-time.

Health IT can also support diagnostic reasoning, help to detect errors and enhance follow-up and tracking (26). Table 2 summarizes a range of health IT approaches and tools that can be used to reduce diagnostic errors. 
Table 2. How health information technology can reduce diagnostic error (22)

\begin{tabular}{|c|c|}
\hline Process & How technology can help \\
\hline $\begin{array}{l}\text { Assists in information } \\
\text { gathering }\end{array}$ & $\begin{array}{l}\text { Helps ensure that prior records and data are } \\
\text { available. Aids the collection of key clinical data, } \\
\text { ensuring that relevant important questions are } \\
\text { asked, improving completeness of parts of the } \\
\text { history that are often neglected (e.g. smoking, } \\
\text { family history and recent travel) and; using trigger } \\
\text { tools to identify patients more likely to have a } \\
\text { diagnostic error (27). }\end{array}$ \\
\hline $\begin{array}{l}\text { Improves information } \\
\text { organization and } \\
\text { display }\end{array}$ & $\begin{array}{l}\text { Decreases the cognitive burden and distraction and } \\
\text { highlights key information to ensure they are not } \\
\text { overlooked. }\end{array}$ \\
\hline $\begin{array}{l}\text { Helps generate a } \\
\text { broad differential } \\
\text { diagnosis }\end{array}$ & $\begin{array}{l}\text { Suggests key follow-up questions or tests to } \\
\text { consider; differential diagnosis generators are } \\
\text { used to offset premature closure around a single } \\
\text { diagnosis. }\end{array}$ \\
\hline $\begin{array}{l}\text { Supports the weighing } \\
\text { of diagnostic } \\
\text { probabilities }\end{array}$ & $\begin{array}{l}\text { Combines clinical data probabilities with diagnostic } \\
\text { testing information to calculate/revise the } \\
\text { probability of a given disease. Facilitate the use } \\
\text { of clinical prediction rules to help improve the } \\
\text { weighing of diagnostic priorities/ probabilities. }\end{array}$ \\
\hline $\begin{array}{l}\text { Helps develop a } \\
\text { diagnostic plan }\end{array}$ & $\begin{array}{l}\text { Helps streamline "next steps" using order sets, } \\
\text { default testing suggestions, guideline packages, } \\
\text { for example, health IT can flag patients with an } \\
\text { unexplained iron deficiency anaemia and automate } \\
\text { or suggest the ordering of appropriate next steps. }\end{array}$ \\
\hline $\begin{array}{l}\text { Improves access to } \\
\text { reference information }\end{array}$ & $\begin{array}{l}\text { Provides access to information, journals, images } \\
\text { and clinical guidelines. }\end{array}$ \\
\hline $\begin{array}{l}\text { Facilitates patient } \\
\text { follow-up }\end{array}$ & $\begin{array}{l}\text { Supports reliable, rather than ad hoc approaches } \\
\text { to patient follow-up. For example, reminder tools } \\
\text { can alert providers about the follow-up of abnormal } \\
\text { tests or the ongoing monitoring of unresolved } \\
\text { problems. }\end{array}$ \\
\hline $\begin{array}{l}\text { Enables and } \\
\text { improves screening } \\
\text { programmes }\end{array}$ & $\begin{array}{l}\text { Improves compliance using automatic reminders } \\
\text { and generating population-based reports. Helps } \\
\text { identify high-risk patients, and patients who have } \\
\text { been lost to follow-up. }\end{array}$ \\
\hline
\end{tabular}




\begin{tabular}{|l|l|}
\hline Process & How technology can help \\
\hline $\begin{array}{l}\text { Provides tools } \\
\text { for collaborative } \\
\text { diagnosis }\end{array}$ & $\begin{array}{l}\text { Facilitates access to second opinions from experts } \\
\text { and makes it easier to solicit colleagues to discuss } \\
\text { challenging cases, for example, via telemedicine or } \\
\text { electronic consultations. }\end{array}$ \\
\hline $\begin{array}{l}\text { Facilitates diagnostic } \\
\text { feedback to clinicians }\end{array}$ & $\begin{array}{l}\text { Establishes a clear chain of events while } \\
\text { documenting the care process more accurately; any } \\
\text { errors ultimately discovered can be fed back and } \\
\text { shared as a learning experience by all. }\end{array}$ \\
\hline $\begin{array}{l}\text { Helps detect } \\
\text { diagnostic errors }\end{array}$ & $\begin{array}{l}\text { Double checks can help catch mistakes; electronic } \\
\text { algorithms can detect missed opportunities for } \\
\text { diagnosis and discrepancies. }\end{array}$ \\
\hline $\begin{array}{l}\text { Facilitates practice } \\
\text { improvement research }\end{array}$ & $\begin{array}{l}\text { Produce epidemiologic data and comparisons } \\
\text { between providers, practices or geographic } \\
\text { locations to allow the exploration of differences } \\
\text { in patient outcomes and adverse events related to } \\
\text { possible diagnostic error. }\end{array}$ \\
\hline
\end{tabular}

\subsection{Improving access to testing}

Access to diagnostic tests could significantly reduce diagnostic error, particularly in low-income countries. This applies to diagnosis both for communicable and non-communicable diseases. Interventions for improving diagnostic services would need to be considered a high priority given the high rates of delayed cancer diagnosis and the difficulties to make diagnoses based on clinical features alone.

Pathology and imaging services to support diagnostic testing are often limited in low-income countries. In these settings, point-of-care testing may offer improved access to diagnostic and laboratory tests for monitoring non-communicable diseases, as well as rapid microbiological tests for infections such as HIV, malaria and sexually-transmitted infections. Health care providers would need to be trained in point-of-care testing and monitoring.

\subsection{Learning from errors}

Health care organizations need ways to routinely assess the quality of diagnostic care. Strategies include tools that identify potential errors or triggers by looking at patients' records, assigning "clinical champions" to encourage reporting and learning from errors, and identifying breakdowns in processes for the follow-up of abnormal findings $(27,28)$.

Finding and analyzing individual cases of diagnostic error provides an opportunity to understand the problem and explore solutions. Non-punitive and non-defensive discussions are valuable for improving awareness and learning how to avoid 
errors. These discussions can take place at clinic meetings and should involve all members of the health care team. Where possible, a formal root cause analysis could become a routine part of the learning effort.

A key challenge is to understand the provider's circumstances at the time of error, thus trying to avoid the hindsight bias that can arise when events are reviewed retrospectively. The goal is to understand why the actions (or inactions) made sense at the time and what could be improved in the future. As well as discussing problems, interventions that worked well should also be identified and emphasized.

\subsection{Further research}

Rigorous research is needed to establish the frequency and cause of diagnostic errors and to evaluate potential solutions.

Most studies about diagnostic error are retrospective and conducted in highincome countries. More robust data is needed from a wider range of primary care settings globally.

Most primary care providers work alone and see a large number of patients. Research is needed to define how best to manage uncertainty in this context.

Research is also needed about optimizing access to knowledge in frontline care. Many knowledge-related diagnostic questions go unanswered as busy providers move on to the next patient (29). Diagnostic decision support tools are underutilized, perhaps due to lack of time and concerns about their efficiency and utility (30).

Another fertile area for investigation is the role of feedback. In addition to learning from their own and other people's errors, providers need to continuously refine and recalibrate their diagnostic skills. Patients could play an important role in providing feedback. Research is needed to identify the most practical and effective methods of providing feedback to providers and how to implement systems that encourage providers and systems to learn from diagnostic errors. The confidential enquiry approach is used in several countries to explore reasons for underlying catastrophic diagnostic errors (31). 


\section{Practical next steps}

Primary care needs to be safe and of high quality in order to maintain and improve health and reduce the reliance on hospital care. Addressing errors, including diagnostic errors, is an important component of improving the safety of primary care.

This patient safety issue affects every country and every diagnosis and involves many stakeholders. Diagnostic errors are relatively frequent and harmful in primary care, but much remains to be learned about them. There is no single intervention to prevent diagnostic errors and solutions need to be rigorously evaluated for benefits and unintended consequences. Research suggests the need for multifaceted interventions that take into account the local context where they are implemented (32).

The United States Institute of Medicine (now known as National Academies of Sciences, Engineering, and Medicine) has published a number of recommendations for improving diagnosis relevant to primary care (33). Raising the standards of training for primary care staff, having family medicine specialists leading teams, reducing workload and ensuring adequate diagnostic facilities are key.

Strategies that WHO Member States could consider prioritizing include:

\section{Supporting the workforce}

- ensuring that the primary care workforce receives education on patient safety. Education about delayed and missed diagnoses should become part of mandatory training and continuing professional development;

- including education about cognitive psychology and systems thinking routinely in curricula so that health care providers understand root causes and the importance of system level approaches;

- making sure that primary care providers have adequate time to appropriately examine and assess patients;

- training providers to incorporate reflections into their clinical practice;

- setting up forums where cases could be discussed;

- facilitating a culture where providers feel comfortable about identifying and discussing errors;

- moving towards trained primary care specialists leading teams;

- encouraging and supporting providers to work in multi-professional teams. 


\section{Including patients as part of the care team}

- encouraging patients to be proactive about asking for information and followup. Providers need to be trained to partner with patients and encourage these questions, so patients become a true partner in the diagnostic process.

\section{Using supportive tools}

- redesigning clinic processes to ensure closed loop systems;

- implementing electronic records with decision support;

- using mnemonics, checklists and web-based support to generate an appropriate differential diagnosis;

- building error-reporting systems to encourage learning from errors;

- using health technologies, such as remote consultations, so that health care providers can get rapid access to specialists and senior colleagues;

- ensuring that information systems present data in useful actionable ways;

- reducing the cognitive load for providers is important, as is ensuring rapid access to information.

\section{Improving diagnostic facilities}

- improving access to diagnostic tests in primary care, including point-of-care testing;

- improving system design by accounting for human factors.

\section{Prioritizing areas for improvement}

- targeting conditions with high rates of diagnostic errors for improvement interventions, such as cancer, cardiovascular conditions and infections;

- investing in research into causes and solutions for diagnostic errors so that interventions can be adapted to the local context.

There is no "one-size-fits-all" approach to reducing diagnostic errors in primary care. For example, there may be a difference between errors made by health care professionals with no postgraduate qualifications versus those trained as specialists. The solutions to error depend on the root causes and the local environment. The root causes of many diagnostic errors are likely to be inadequate clinical training, work overload, lack of essential facilities and other systems level issues. Addressing these issues lies at the heart of safer primary care. 


\section{Concluding remarks}

Primary care services are at the heart of health care in many countries. They provide an entry point into the health system and directly impact on people's well-being and their use of other health care resources. Unsafe or ineffective primary care may increase morbidity and preventable mortality, and may lead to the unnecessary use of scarce hospital and specialist resources. Thus, improving safety in primary care is essential when striving to ensure universal health coverage and the sustainability of health care. Safer primary care is fundamental to the United Nations Sustainable Development Goals, particularly to ensure healthy lives and promote well-being for all at every age.

Understanding the magnitude and nature of harm in primary care is important because a significant proportion of health care is offered in this setting, yet there is little clarity about the most effective ways to address safety issues at this level.

This monograph summarizes the evidence and experience to understand and address diagnostic errors in order to improve patient safety in primary care. However, interventions to prevent diagnostic errors would need to be implemented in conjunction with other important aspects covered in this series.

The Technical Series on Safer Primary Care addresses selected priority areas that WHO Member States could prioritize, according to local needs. This section summarizes the key messages from all of the monographs and provides a list of 10 key actions that are likely to have the most impact on improving safety in primary care. Links to online toolkits and manuals are also referenced in order to provide practical suggestions for countries and organizations committed to moving forward this agenda.

\section{Set local priorities}

Countries and regions differ and a strategy that works well in one area may not transfer well to another. Similarly, issues in need of improvement in some regions may not be a priority for others. In seeking to improve safety in primary care, countries could use local information about their safety issues to identify key priorities at the national or regional level. Priority setting could be accomplished by drawing on input from patients and professionals, sourcing local statistics on safety issues and comparing key themes from the literature with local circumstances (34).

Checklists are also available to help identify potential patient safety issues such as environmental risks in primary care services (35).

One practical way to move forward is creating mechanisms for bringing together key stakeholders to consider the local information available and develop strategic and operational plans for improving safety in primary care. Communicating proposed priorities widely and amending them based on feedback from health 
care professionals and patients would help to obtain their buy-in, as well as raise awareness of the importance of improving patient safety in primary care.

Regular measurement of safety related performance indicators could be considered as one of the priorities. Policy-makers can use measurements to help identify local issues where performance is suboptimal and then evaluate different types of interventions for improvements. Priorities could be reviewed every few years to ensure that they remain in line with local needs and good practice.

\section{Take a wider systems approach to improving safety}

Although the series has described specific technical areas, each monograph refers to interlinkages with other areas. Focusing on improving just one factor may not have a large or sustainable impact on patient safety overall. It may be important to simultaneously improve communication with patients, train health care professionals and introduce new tools to support more streamlined care.

Taking a systems approach to safer primary care means looking at how different components relate to one another and considering various factors which could influence safety. These include factors such as workforce availability and capability.

A practical systems level initiative is to focus on increased communication and coordination across different types of care including primary, secondary and also social care. This may include strengthening technical systems for sharing records and communicating what is happening.

It is also important to build relationships between care professionals. At a policy level, this may involve considering how to develop supportive infrastructure, such as having a directory of services to help build networks of professionals and align resources. If hospital, primary care and social care professionals are able to meet and discuss safety issues, this could foster supportive relationships and increase understanding of each other's roles. Regional forums or meetings could be set up so that professionals from different organizations can get to know each other and share their successes and challenges in improving patient safety.

Manuals and reference lists are available with further ideas for improving coordination and reducing fragmentation across systems $(36,37)$.

\section{Communicate the importance of safety in primary care}

Policy-makers, health care professionals, patients and families may not always be aware that there are important safety issues to consider in primary care. Raising awareness of this as a priority area will help stakeholders to understand why safety in primary care is essential to improve people's well-being and for safeguarding scarce health care resources.

Serious consequences due to the lack of safety in primary care, particularity relating to poor transitions of care between primary and other levels, and administrative, diagnostic and medication errors could be highlighted to raise awareness on the need to improve patient safety in primary care. 
Practical ways to increase awareness include incorporating safety-related information into the training of health professionals, communicating effectively to professionals and patients through channels that would be most appropriate for them and spreading key messages through media campaigns. A communications plan could be developed in tandem with local priority setting discussed earlier.

\section{Focus on building a positive safety culture}

Effective leadership and supportive culture are essential for improving safety in primary care. This means creating an environment where professionals and patients feel able to speak up about safety issues that they are concerned about, without fear of blame or retribution. It means promoting an environment where people want to report risks and safety incidents in order to learn from them and reduce their recurrence, and where incidents are seen as caused largely by system failures rather than by individuals. This also includes the importance of having feedback mechanisms in place to explain any improvements made after safety issues have been raised. Promoting transparency is key to building a strong safety culture.

A number of tools are available describing approaches to support the development and measurement of a positive safety culture $(38,39)$.

Practical steps that could be taken to strengthen safety culture include: leadership walkrounds, whereby senior managerial and clinical leaders "walk the floor" (in this case, leaders visiting clinics and speaking with staff and patients about what is working well and not so well); starting team meetings with a patient story; using reflective practice to focus on safety issues, such as audits and having mechanisms for reporting safety issues, such as through regular team meetings. Such approaches may need to be adapted for use in smaller primary care clinics. Regardless of the specific method, the focus should be on raising awareness, encouraging safety discussions and taking concrete follow-up actions to build a safety culture.

\section{Strengthen ways of measuring and monitoring patient safety}

It is important to measure and monitor patient safety improvements over time. This may include having clear definitions of patient safety incidents and indicators to be measured annually, setting up national or local incident reporting systems where data is compiled regularly, or using tools to assess patient experiences and measure improvements in patient safety.

Using checklists in individual practices can both improve the quality of care and act as a structured form of record keeping. A number of examples of checklists to improve safety monitoring are available (40).

Data quality is fundamental to measuring improvements in patient safety. If accurate and comprehensive medical records are not kept, then errors and omissions are more likely to occur. As health systems mature, clinical governance processes tend to strengthen. This includes having processes for managing risks and identifying strategies for improvement. 
A number of tools are available to measure and monitor different aspects of safety in primary care and countries could examine what is currently available and adapt materials based on local priorities $(41,42)$.

\section{Strengthen the use of electronic tools}

The adoption of electronic tools will be critical to improving safety in many ways. Examples include the use of electronic health records for more accurate and complete patient records; timely and reliable sharing of health data; supporting the diagnosis, monitoring and management of diseases and conditions; effecting behaviour change and reduction of health risk, and empowering and engaging patients and families in their own care. eHealth can help structure communication between professionals in a way that reduces errors and improves coordination. It can reduce unnecessary consultations and hospitalizations and improve access to knowledge about health conditions and their management for both professionals and patients. However, to achieve their full potential, electronic tools need to be integrated with other parts of service delivery and adapted to the local context.

It takes time and resources to implement electronic tools, and requires the capacity to use and maintain them. It is therefore important to be strategic and to understand the foundations and design of systems in order to ensure the best return on investment. Linking the implementation of electronic tools in local settings to a national eHealth strategy is essential as it provides the foundation, justification and support needed to go forward in a coordinated way.

Irrespective of the status of the health system, it is important to strengthen the use of electronic systems to improve patient safety. For some countries, this may involve the introduction of electronic health records to replace paper records. For others, it may mean having integrated electronic systems between primary care and hospital and social care, or making the tools easier for professionals and patients to use. Countries could draw on lessons learned from other countries about implementing electronic health records, including the challenges faced and how these were overcome, and what best practices could be applicable to their own setting.

\section{Involve patients and family members}

Empowering and encouraging patients to speak up, for example when something does not seem right or when a symptom is inadequately explained, can be fundamental to improving patient safety. Family members play a key role as advocates and informal carers and therefore supporting and educating them can help to improve safety.

Proactive engagement of patients and families can help to accelerate the implementation of health care safety initiatives. When systems open themselves up to patients rather than being reactive, this is likely to improve system efficiency and the quality of care.

A number of tools have been evaluated to enhance patient and family involvement and awareness, including those with limited or low literacy skills (43-46). 


\section{Strengthen workforce capacity and capability to improve safety}

There is a need to strengthen the primary care workforce in many settings by training a large pool of generalist workers, including doctors, nurses and those with supporting roles.

Strengthening the workforce also involves focusing on recruitment and retention, including taking steps to enhance the physical and physiological safety of health care workers. Professional burnout, fatigue and stress can all adversely affect patient safety.

The education and training of health care professionals to manage and minimize potential risks and harm that can occur in primary care are central to improving safety at all levels of care. This includes providing training on patient safety for students (including students who may not be training to work in primary care to ensure understanding across the different care pathways), multidisciplinary and inter-professional education, as well as continuing professional development. A number of free training course materials are available to help with this (47-49). As a further step, consideration could be given to making involvement in safety and quality improvement a requirement for ongoing training and professional licensure.

In addition to formal education, informal approaches could also be applied to build the capacity of health workforce to improve safety. This may include holding regional meetings and coaching sessions to review patient safety incidents and areas for improvement, and holding small team meetings to upskill staff.

\section{Focus on those at higher risk of safety incidents}

Some people are at greater risk of safety incidents in primary care. These include children, older people, those living in residential care or nursing homes and people with multiple health conditions. People with simultaneous mental health and physical health issues are also at increased risk of safety incidents.

Focusing on groups at higher risk may improve the quality and safety of care by providing more personalized care and ensuring smoother transitions between and within services. For instance, upskilling professionals in how to identify and treat depression may have an impact given the high rate of adverse events among those with combined mental and physical health issues.

Across the world, most systems were not designed to care for people with multiple health conditions. Systems may thus need to focus more on what can be done to improve care for people with multiple conditions, including whether social interventions would be more worthwhile than increasing medicalization.

A number of guidelines and toolkits suggest practical steps to better support people at higher risk of safety incidents (50-54). 
10. Celebrate successes and share learning with others

Local teams, regions and countries should celebrate their successes and share learning with others. Hearing what has worked well can spark ideas in others and help to continue the momentum towards safer primary care.

Ongoing research plays a key role in identifying what works best to improve safety and how to implement best practices and success stories across diverse care settings. Although the technical series has drawn together a wide range of evidence and expertise, it has also highlighted a number of gaps about what works best to improve patient safety in the primary care context. By continuing to promote learning through research, and publishing and disseminating findings, countries could contribute to knowledge in this area. 


\section{Contributors}

\section{Leadership group}

\section{Aziz Sheikh}

University of Edinburgh

Edinburgh, United Kingdom

Liam Donaldson

WHO Envoy for Patient Safety

World Health Organization

Geneva, Switzerland

Neelam Dhingra-Kumar

World Health Organization

Geneva, Switzerland

\section{David Westfall Bates}

Harvard University

Boston, United States of America

Edward Kelley

World Health Organization

Geneva, Switzerland

Itziar Larizgoitia

World Health Organization

Geneva, Switzerland

\section{Project coordination and editorial support}

Sukhmeet Singh Panesar

Baylor College of Medicine

Houston, United States of America

Chris Singh

The Evidence Centre

Wellington, New Zealand

\section{Authors}

\section{Hardeep Singh}

Houston Veterans Affairs Health

Services Research Center of Innovation

Houston, United States of America

\section{Igho Onakpoya}

University of Oxford

Oxford, United Kingdom

\section{Matthew Thompson}

University of Washington

Seattle, United States of America

\section{Debra de Silva}

The Evidence Centre

London, United Kingdom

\author{
Mark Graber \\ State University of New York \\ New York, United States of America

\section{Gordon Schiff} \\ Harvard Medical School Center for \\ Primary Care Academic Innovations \\ Collaborative \\ Boston, United States of America
}




\section{Other contributors}

Ahmed Al-Mandhari

Quality Assurance Center

Ministry of Health, Oman

John Ely

University of lowa

lowa City, United States of America

Tejal Gandhi

National Patient Safety Foundation

Boston, United States of America

Amanda Howe

University of East Anglia

Norwich, United Kingdom

\section{Edward Mann}

World Health Organization

Geneva, Switzerland

Chow Mun Hong

SingHealth Polyclinics

Singapore, Singapore

Ruth Wilson

Queen's University

Kingston, Canada
Elzerie de Jager

World Health Organization

Geneva, Switzerland

Paul Epner

Society to Improve Diagnosis in

Medicine

Evanston, United States of America

Katherine Hayes

World Health Organization

Geneva, Switzerland

Olga Kostopoulou

Imperial College London

London, United Kingdom

\section{Paul Shekelle}

West Lost Angeles Veterans Affair

Medical Centre

Los Angeles, United States of America 


\section{References}

1 Kostopoulou O, Delaney BC, Munro CW. Diagnostic difficulty and error in primary care - a systematic review. Fam Pract. 2008;25(6):400-13.

2 Graber ML, Franklin N, Gordon R. Diagnostic error in internal medicine. Arch Intern Med. 2005;165(13):1493-9.

3 Singh H, Giardina TD, Meyer AND, Forjuoh SN, Reis MD, Thomas EJ. Types and origins of diagnostic errors in primary care settings. JAMA Intern Med. 2013;173(6):418-25.

4 Singh H, Meyer AND, Thomas EJ. The frequency of diagnostic errors in outpatient care: estimations from three large observational studies involving US adult populations. BMJ Qual Saf. 2014;23(9):727-31.

5 Singh H. Editorial: Helping health care organizations to define diagnostic errors as missed opportunities in diagnosis. Jt Comm J Qual Patient Saf. 2014 Mar;40(3):99-101.

6 Singh H, Schiff GD, Graber ML, Onakpoya I, Thompson MJ. The global burden of diagnostic errors in primary care. BMJ Qual Saf 2016;0:1-11. doi:10.1136/ bmjqs-2016-005401.

7 Singh H, Thomas EJ, Wilson L, Kelly PA, Pietz K, Elkeeb D, et al. Errors of diagnosis in pediatric practice: a multisite survey. Paediatrics 2010;126(1):70-9.

8 Casalino LP, Dunham D, Chin MH, Bielang R, Kistner EO, Karrison TG, et al. Frequency of failure to inform patients of clinically significant outpatient test results. Arch Intern Med. 2009;169(12):1123-9.

9 Singh H, Esquivel A, Sittig DF, Murphy DR, Kadiyala H, Schiesser R, et al. Followup actions on electronic referral communication in a multispecialty outpatient setting. J Gen Intern Med. 2011;26(1):64-9.

10 Schiff GD, Kim S, Abrams R, Cosby K, Lambert B, Elstein AS. Diagnosing diagnostic errors: lessons from a multi-institutional collaborative project. In: Advances in patient safety: from research to implementation (vol. 2: Concepts and methodology). Rockville (MD): Agency for Healthcare Research and Quality; 2005:255-78.

11 Silk N. What went wrong in 1000 negligence claims. Health Care Risk Report. London: Medical Protection Society; 2000:14-16.

12 Leslie T, Mikhail A, Mayan I, Cundill B, Anwar M, Bakhtash SH, et al. Rapid diagnostic tests to improve treatment of malaria and other febrile illnesses: patient randomised effectiveness trial in primary care clinics in Afghanistan. BMJ. 2014;348:g3730. 
13 Szczuka I, Pawlicka L, Kus J, Leowski J, Roszkowski K. Analysis of diagnostic errors and recommendations of diagnostic procedures in bacteriologically negative pulmonary tuberculosis. Pneumonol Alergol Pol. 1998;66(1-2):17-23.

14 Liu L, Johnson HL, Cousens S, Perin J, Scott S, Lawn JE, et al. Global, regional, and national causes of child mortality: an updated systematic analysis for 2010 with time trends since 2000. Lancet. 2012;379(9832):2151-61.

15 Levels and trends in child mortality, estimates developed by the UN inter-agency group for child mortality estimation. NewYork: United Nations Children's Fund; 2014.

16 Wallace E, Lowry J, Smith SM, FaheyT.The epidemiology of malpractice claims in primary care: a systematic review. BMJ Open. 2013;3(7):e002929.

17 Singh H, Graber ML. Improving diagnosis in health care - the next imperative for patient safety. N Engl J Med. 2015;373:2493-5.

18 Singh H, Graber ML, Kissam SM, Sorensen AV, Lenfestey NF, Tant EM, et al. System-related interventions to reduce diagnostic errors: a narrative review. BMJ Qual Saf. 2012;21(2):160-70.

19 Kostopoulou O, Russo JE, Keenan G, Delaney BC, Douiri A. Information distortion in physicians' diagnostic judgments. Med Decis Making. 2012;32(6):831-9.

20 Ely JW, Graber ML, Croskerry P. Checklists to reduce diagnostic errors. Acad Med. 2011;86(3):307-13

21 McDonald KM, Bryce C, Graber M.The patient is in: patient involvement strategies for diagnostic error mitigation. BMJ Qual Saf. 2013;22 Suppl 2:ii33- ii9.

22 El-Kareh R, Hasan O, Schiff GD. Use of health information technology to reduce diagnostic errors. BMJ Qual Saf. 2013;22(Suppl. 2):ii40-ii51.

23 Starfield B, Shi L, Macinko J. Contribution of primary care to health systems and health. Milbank Q. 2005;83(3):457-502.

24 Graber ML, Trowbridge RL, Myers JS, Umscheid CA, Strull W, Kanter MH. The next organizational challenge: finding and addressing diagnostic error. Jt Comm J Qual Saf. 2014;40(3):102-10.

25 Noro R, Hubaux JP, Meuli R, Laurini RN, Patthey R. Real-time telediagnosis of radiological images through an asynchronous transfer mode network: the ARTeMeD project. J Digit Imaging. 1997;10(3 Suppl. 1):116-21.

26 Singh H, Naik A, Rao R, Petersen L. Reducing diagnostic errors through effective communication: harnessing the power of information technology. J Gen Intern Med. 2008;23(4):489-94.

27 Graber ML. The incidence of diagnostic error in medicine. BMJ Qual Saf. 2013 Oct; 22(Suppl 2): ii21-ii27.

28 Okafor N, Payne VL, ChathampallyY, Miller S, Doshi P, Singh H. Using voluntary reports from physicians to learn from diagnostic errors in emergency medicine. Emerg Med J. 2016;33(4):245-52. 
29 Ely JW, Osheroff JA, Ebell MH, Chambliss ML, Vinson DC, Stevermer JJ, et al. Obstacles to answering doctors' questions about patient care with evidence: qualitative study. BMJ. 2002;324(7339):710.

30 Sittig DF, Krall MA, Dykstra RH, Russell A, Chin HL. A survey of factors affecting clinician acceptance of clinical decision support. BMC Med Inform Decis Mak. 2006;6:6.

31 Harnden A, Mayon-White R, Mant D, Kelly D, Pearson G. Child deaths: confidential enquiry into the role and quality of UK primary care. $\mathrm{Br} \mathrm{J}$ Gen Pract. 2009;59(568):819-24.

32 Sittig DF, Kahol K, Singh H. Sociotechnical evaluation of the safety and effectiveness of point-of-care mobile computing devices: a case study conducted in India. Stud Health Technol Inform. 2013;192:515-19.

33 Improving diagnosis in health care: National Academies of Sciences, Engineering, and Medicine. 2015. Washington, DC: The National Academies Press.(https://www.nap.edu/catalog/21794/improving-diagnosis-in-healthcare, accessed 19 September 2016).

34 Improving safety in primary care. London:The Health Foundation; 2011; (http:// www.health.org.uk/publication/improving-safety-primary-care, accessed 19 September 2016).

35 Primary risk in management services. Cardiff: Public Health Wales; 2015 (http://www.wales.nhs.uk/sites3/page.cfm?orgid=457\&pid=73076, accessed 19 September 2016).

36 The improving chronic illness care program. Primary care team guide. Seattle, WA:The MacColl Center; 2016 (http://www.improvingchroniccare.org/ downloads/ reducing_care_fragmentation.pdf accessed 19 September 2016).

37 Care coordination resource list. Beerse: Janssen Pharmaceuticals Inc.; 2014 (http://www.janssenpharmaceuticalsinc.com/sites/default/files/pdf/Carecoordination-resource-list.pdf accessed 19 September 2016).

38 Seven steps to patient safety. London: National Patient Safety Agency; 2004 (http://www.nrls.npsa.nhs.uk/resources/collections/seven-steps-to-patientsafety/?entryid45=59787, accessed 19 September 2016).

39 Safety and improvement in primary care. Edinburgh: NHS Education for Scotland; $2011 \quad$ (http://www.nes.scot.nhs.uk/media/3437356/Safety-andImprovement-Educational\%20Resources-A-Toolkit-for\%20Safe-EffectivePerson-Centred-Care.pdf, accessed 19 September 2016).

40 Accreditation handbook for ambulatory health care Skokie, IL: Accreditation Association for Ambulatory Health Care, (http://www.aaahc.org/Global/ Handbooks/2015_Accreditation\%20Handbook_FNL_5.22.15.pdf, accessed 19 September 2016).

41 Tools. Cambridge, MA: Institute for Healthcare Improvement; 2016 (http://www. ihi. org/resources/Pages/Tools/default.aspx, accessed 19 September 2016). 
42 Patient safety toolkit. London: Royal College of General Practitioners; (http:// www.rcgp.org.uk/clinical-and-research/toolkits/patient-safety.aspx, accessed 19 September 2016).

43 Partnering with patient and families to enhance safety and quality: a mini toolkit. Bethesda, MD: Institute for Patient- and Family-Centered Care; 2013 (http://www. ipfcc.org/tools/Patient-Safety-Toolkit-04.pdf, accessed 19 September 2016).

44 Health literacy toolkit for low-and middle-income countries. New Delhi: World Health Organization Regional Office for South-East Asia; 2015 (http://www. searo.who.int/entity/healthpromotion/documents/hl_tookit/en/ accessed 19 September 2016).

45 Health literacy universal precautions toolkit. Rockville, MD: Agency for Healthcare Research and Quality; 2016 (http://www.ahrq.gov/professionals/ quality-patient-safety/quality-resources/tools/literacy-toolkit/index.html, accessed 19 September 2016).

46 The Boston Medical Center patient navigation toolkit. Boston, MA; The AVON Foundation and the National Cancer Institute; (https://nciphub.org/ resources/1600/download/BMC_Patient_Navigation_Toolkit_-_Vol_1.pdf, accessed 19 September 2016).

47 Patient safety research: introductory course (on-line). Geneva: World Health Organization; 2016 (http://www.who.int/patientsafety/research/online_course/ en/, accessed 19 September 2016).

48 Master in Health Administration. 65+ free online healthcare courses. Davis, CA; University of California; 2016 (http://mhadegree.org/free-online-healthcarecourses/, accessed 19 September 2016).

49 Patient safety network. Training catalog. Rockville, MD: Agency for Healthcare Research and Quality; 2016 (https://psnet.ahrq.gov/pset, accessed 19 September 2016).

50 Age-friendly primary health care centres toolkit. Geneva: World Health Organization; $2008 \quad$ (http://www.who.int/ageing/publications/AF_PHC_ Centretoolkit.pdf, accessed 19 September 2016).

51 Patient safety collaborative manual. Hamilton/Mount Gambier/Warrnambool; Greater Green Triangle/Australian Primary Health Care Research Institute; 2016 (http://www.greaterhealth.org/resources/patient-safety-collaborative-manual, accessed 19 September 2016).

52 Toolkit for general practice in supporting older people with frailty and achieving the requirements of the unplanned admissions enhanced (2014). NHS England South Region; 2014 (http://www.nhsiq.nhs.uk/media/2630779/toolkit_for_general_ practice_in_supporting_older_people.pdf, accessed 19 September 2016).

53 Stay independent falls prevention toolkit for clinicians. Health Quality and Safety Commission New Zealand; 2015 (http://www.hqsc.govt.nz/our-programmes/ reducing-harm-from-falls/publications-and-resources/publication/2232/, accessed 19 September 2016). 
54 Prevention and control of noncommunicable diseases: guidelines for primary health care in low-resource settings. Geneva: World Health Organization; 2012 (http://apps.who.int/iris/bitstream/10665/76173/1/9789241548397_eng.pdf, accessed 19 September 2016). 


\section{Technical Series: Safer Primary Care}

This monograph on 'Diagnostic errors' is part of a technical series of nine monographs which explore different aspects of safety in primary care services. The other topics include:

\section{PATIENTS}

- Patient engagement

\section{HEALTH WORKFORCE}

- Education and training

- Human factors

\section{CARE PROCESSES}

- Administrative errors

- Medication errors

- Multimorbidity

- Transitions of care

TOOLS AND TECHNOLOGY

- Electronic tools

For more information, please contact:

Department of Service Delivery and Safety

World Health Organization

Avenue Appia 20

CH-1211 Geneva 27 Switzerland

Email: patientsafety@who.int

www.who.int/patientsafety 